\title{
Visitor Perceptions of Ancient Egyptian Human Remains in Three United Kindom Museums
}

\author{
Hugh Kilmister \\ The Petrie Museum of Egyptian Archaeology, UCL
}

\begin{abstract}
Although the issues of retention and display of human remains have become topical over the last decade, the thoughts of museum visitors about this topic have not been registered, despite their being the museums' main stakeholder. The vast majority $(82.5 \%)$ of 300 respondents questioned in the summer of 2002 at three British museums displaying ancient Egyptian human remains supported the idea of having these remains on display. However, a small percentage of visitors $(14.2 \%)$ wanted the remains displayed in a "more appropriate and respectful environment", and this may be the key future challenge for collections with human remains that have no cultural descendants. This paper summarises research into visitor perceptions of ancient Egyptian human remains in museum collections and on display in the United Kingdom and suggests further research into the various aspects of human remains in museums, particularly regarding more recent remains or those with cultural descendants.
\end{abstract}

\section{Introduction}

The issues of retention and display of human remains have become increasingly topical and relevant to the museum profession (see Butler 2001; Layton 1989; Parker Pearson 1995). Rather than try to cover all the many and varied issues and groups involved, this work concentrates solely on visitor attitudes to the display of ancient Egyptian human remains. However, some of the conclusions reached in this work could equally apply to other collections of human remains without cultural descendants.

Archaeologists and museum professionals now have to be aware of how to deal sensitively with the issues raised by excavating human remains and maintaining them as part of their collections. In their 2002 Code of Ethics for Museums, the Museums Association states that:

All those who work for or govern Museums should ensure that they: Dispose of human remains with sensitivity and respect for the beliefs of communities of origin.

(Museums Association 2002: 16)

Equally significant was the formation of a Working Group on Human Remains in May 2001 by the United Kingdom Minister for the Arts. The establishment of this group led directly on from the House of Commons Culture, Media and Sport (DCMS), "Report on Cultural Property" (Bauer 2001). The Working Group has been charged with, amongst other things:

Examining the current legal status of human remains within the collections of publicly funded Museums and to consider the desirability of a Statement of Principles relating to the care and safekeeping of human remains and to the handling of requests for return.

(Department for Culture, Media and Sport 2001) 
Prompted by continued demands of indigenous peoples for the return of human remains, it was deemed necessary for the Working Group not only to calculate the potential scale of human remains held in United Kingdom museums, but also to provide guidance to the museum profession about dealing with the difficult issues involved in retention and display of such remains. The establishment of the Working Group on Human Remains also came as a result of the wider issues involved in retaining human remains, especially in light of the public uproar that followed the Alder Hey scandal, where a histopathologist retained material from infant autopsies without consent. This led to the establishment of the Retained Organs Commission (National Health Service 2002).

However, in wanting to establish a more ethical treatment of human remains, museums have paid, and continue to pay, little attention to their main stakeholders - their visitors. Visitor perceptions of what a museum should display are vital in establishing what society as a whole may or may not find acceptable. The Alder Hey scandal is a good indicator of how powerful public opinion can be in affecting change in public policy.

Although some museums may have decided that having, let alone displaying, human remains is perhaps inappropriate, "BodyWorlds", an exhibition of 32 plastinated modern human bodies, attracted more than 840000 visitors in London during 2002 and early 2003 (BodyWorlds 2002). It was this apparent contradiction that first prompted this research. Using museums' own audiences as an indicator, I was interested to ascertain whether the museum profession was becoming unduly sensitive about the issues surrounding human remains. By surveying visitors about their attitudes to the less contentious human remains of Egypt's past, an attempt was made to understand whether the visiting public felt that it was inappropriate for museums to continue to hold these remains or if they wholeheartedly approved of their display.

In light of the conclusions reached in this research, a useful comparative exercise for future research would be to consider, in a similar manner to that presented here, the curation and display of more recent human remains and those that have cultural descendants. Such additional questioning of museum stakeholders would further the understanding of museum professionals about the range of public opinions relating to the curation and display of human remains.

\section{Methodology}

The initial groundwork for the survey began in February 2002. As part of a larger survey to establish "Who visits the Petrie Museum?", 100 respondents were asked two questions about the display of human remains in the Petrie Museum. The first question asked visitors to express their thoughts on seeing these remains, and question two required them to choose one of the following three options that best summed up their views on museums having and displaying human remains:

A) Museums are not appropriate places for human remains and they should be sent back to their country of origin. 
$B$ ) It is okay for museums to have human remains but they should remain in storage.

C) Museums should be allowed to display whatever is part of their present collection.

Option $C$ was chosen by 81 respondents, whilst six chose $A$ and nine chose $B$. For three respondents none of the above options were appropriate. Respondents gave a variety of thoughts on the experience of seeing the remains. Many felt "ambivalent", others that it was "to be expected" in an Egyptian collection and that it was "educational". Although many chose option $C$, they still felt that any display of remains should be in context, respectful and informative.

Therefore, by the time pilot questions were being developed in May 2002, there was already a fairly clear, if general, indication of visitor perceptions towards ancient Egyptian human remains on display in museums. Before the actual survey questions were asked at the Petrie Museum at the end of June 2002 (see Appendix), the questions underwent a number of adjustments.

Initially, question one gave respondents a choice of definitions as to what they thought human remains were. This caused confusion when the pilot survey was conducted in June 2002, so in the final survey respondents were asked to provide their own definitions. In addition, it was felt that it was important to elicit the responses of museum professionals and other related specialists in constructing questions that they felt were relevant to this issue. David Prince, director of a market research company, and an interested party, suggested that it would be useful to include a question on what respondents thought would happen to themselves after death, and also to ask the religious affinity of respondents, both of which were incorporated into the final survey. Tristram Besterman, Director of the Manchester Museum, suggested that if respondents chose option $D$ of question five ("It is not appropriate for the museum to hold human remains"), they should be given an opportunity to qualify their response. This added a sixth question allowing respondents to explore what they thought should happen to the remains if they felt museums in the United Kingdom were not an appropriate place for them.

In developing the survey questions, it was crucial to elicit a range of views from respondents. It was useful to establish the ways in which the visiting public, over and against museums professionals, defined human remains. Most importantly, as a justification for displaying remains, it was felt necessary to establish whether people had benefited educationally from viewing them in the three collections in the study and, if so, what exactly they had learnt. A further qualitative, ethical question was set to find out whether people would be opposed to viewing modern human remains i.e. those less than 100 years old. This was felt to be a good test of whether people's views towards ancient and modern remains were contradictory.

Of all ten questions, question five was the most important to this survey, as respondents were asked to choose the view offered that best summed up their thoughts about human 
remains in the displays. The options offered were broadened from the initial survey in February 2002, and four distinct categories were presented. These gave respondents the choice of allowing the museum to do "whatever it sees fit" with the remains, to "show more respect in the way that it displays human remains", that "it is okay for the museum to hold human remains but they should be kept in store and not displayed" and finally, that "it is not appropriate for museums to hold human remains". For each of these choices respondents were encouraged to discuss what they had chosen.

The final four questions were quantitative and demographic, establishing the sex, age, religion and educational level of respondents. The responses to these questions were used to look for patterns of responses to certain other survey questions.

By mid-June 2002 the final ten survey questions were piloted with ten respondents at the Petrie Museum, and approval had been given to undertake this work in the Petrie Museum of Egyptian Archaeology, UCL, the Manchester Museum and the British Museum. Respondents were chosen randomly in each museum and were asked the survey questions at the exit point of the gallery/galleries that contained the human remains. In order to have data that would present significant and worthwhile findings, 100 respondents were interviewed in each of the three participating institutions. Each institution was chosen for specific reasons. The British Museum was chosen because of the quantity both of its audiences and of the human remains on display. The Manchester Museum was important because of the scientific work undertaken on its ancient Egyptian human remains. The Petrie Museum of Egyptian Archaeology, UCL was chosen as it is a university museum with a specialist collection, and therefore recieves a more 'specialist' audience.

The Statistical Package for the Social Sciences (SPSS) was chosen to analyse the raw data. Percentage statistics were produced for all the questions, responses were coded, and these codes were imported into a spreadsheet. Each possible response to a question was given a numerical code so that responses could be processed statistically. Regression analysis (to highlight the best predictor factors for something), 1 sample t-tests (to compare two sets of data for a statistical difference), and paired sample correlations (to show that there could be a relationship in the data) were carried out on some data.

\section{Results and Discussion}

In the initial study, the results for each museum were considered individually, however for this paper only the overall, cumulative results for the three collections are presented.

\section{Question One}

In this question respondents were asked what they thought human remains were (Table 1). As reflected individually over the three collections, bodies, body parts, bones and a combination answer of skin, bones and mummies were chosen by 280 of the 300 respondents. Surprisingly, despite these museums having mummies or mummy parts on display, only 11 respondents thought of such material specifically when defining human remains. 


\begin{tabular}{|l|c|c|}
\hline Human Remains & Frequency & Percentage \\
\hline 1) mummy parts & 3 & 1.0 \\
\hline 2) mummy & 8 & 2.7 \\
\hline 3) body & 58 & 19.3 \\
\hline 4) body parts & 86 & 28.7 \\
\hline 5) bones & 55 & 18.3 \\
\hline 6) skin & 2 & 0.7 \\
\hline 7) hair & 0 & 0 \\
\hline 8) tissue & 0 & 0 \\
\hline 9) organs & 0 & 0 \\
\hline 10) combination & 81 & 27.0 \\
\hline 11) other & 7 & 2.3 \\
\hline TOTAL & 300 & 100.0 \\
\hline
\end{tabular}

Table 1. Responses to question one.

Question Two

The answers to this question revealed that as a result of viewing the human remains in these collections, $80 \%$ of respondents felt that they had learnt more than they previously knew about the ancient Egyptians. Knowledge gained included understanding more about burial techniques and funerary practices in ancient Egypt, the personal grooming of individuals and the size and stature of the bodies. Overall $20 \%$ of respondents claimed not to have learnt from viewing the remains, but this could be explained in part by some respondents having previously visited the galleries or already being familiar with the information presented prior to their visit to the museums.

These data were put through a 1 sample t-test with the result that $80 \%$ was a significant difference. This may be interpreted as a very positive finding. As highlighted in the results of other questions, the public seemed more comfortable viewing human remains if there is deemed to be an educational value, therefore, respondents may feel that they were deriving benefit from their experience.

\section{Question Three}

For this question respondents were asked whether their thoughts would be different if they were viewing modern human remains, i.e. less than one hundred years old. Of the $80 \%$ of respondents who were comfortable viewing ancient remains, over half (54.7\%) of these would be sensitive to viewing modern remains. The results of this question, when put through a 1 sample t-test, suggested that a significant number of respondents would feel uncomfortable viewing recent remains. Many respondents were happy viewing ancient human remains because they are so far removed from our own time, and a large proportion said that there was an educational reason for viewing them. Many respondents felt it would be disrespectful to view modern human remains because the bodies would be "too close in time to us today", with potential living relatives. Also many respondents could see no historical reason for a display of this nature. Some respondents commented that displaying modern remains would be "distasteful", and respondents were concerned that living relatives would be distressed by this sort of exhibition. From the overall results of this question we can draw the inference that respondents' attitudes to viewing human remains are contradictory. The real test may, therefore, be an exhibition of both ancient and modern remains to see which the public felt most ambivalent or sensitive about and why. 


\section{Question Four}

This question asked respondents to consider what they thought would happen to them after death (Table 2). Almost half of all respondents $(49 \%)$ believed that death was not the end, that a soul or spirit continues in some "other place". Many respondents $(29 \%)$ believed that the body rots and is only a vessel that gets "left behind", which partly explains the views of those respondents who were ambivalent about seeing both ancient and modern remains. Interestingly, after studying the responses to question four in combination with the age demographics, it was noted that most young people (16-34 age category) were greatly challenged by this question. In the 16-24 age bracket, perhaps unsurprisingly, few had even considered the issue, and for some it proved traumatic to even consider the concept.

\begin{tabular}{|l|c|c|}
\hline Response & Frequency & Percentage \\
\hline 1) no & 46 & 15.5 \\
\hline 2) yes & 248 & 82.5 \\
\hline 3) no opinion & 6 & 2.0 \\
\hline TOTAL & 300 & 100.0 \\
\hline
\end{tabular}

Table 3. Responses to the option that "museums should be allowed to display their human remains in "whatever way they see fit" (question five).

\begin{tabular}{|l|c|c|}
\hline Response & Frequency & Percentage \\
\hline 1) no & 234 & 77.8 \\
\hline 2) yes & 42 & 14.2 \\
\hline 3) no opinion & 24 & 8.0 \\
\hline TOTAL & 300 & 100.0 \\
\hline
\end{tabular}

Table 4. Responses to the option that "more respect should be shown" to human remains (question five). seven respondents $(2.3 \%)$ thought that the remains "should be kept in storage and not displayed". Nine respondents (3\% of all those questioned) suggested that a separate "burial area" would be more appropriate, although this was not an option, as such.

\section{Question Six}

Only three respondents to this question (one in each museum $=1 \%$ of the total number of respondents) thought that it was inappropriate for United Kingdom museums to have these remains, and they would like them to be buried either here or returned to Egypt. Based on these data there is, therefore, overwhelming support (99\%), for the retention of these remains. Various paired sample correlations were done on this data, to try to 
establish if respondents' answers to different questions could be correlated, but nothing of statistical significance was found.

Questions seven to ten were demographic in nature. They were included to establish whether a person's age, sex, religion or educational background could be used to predict responses to question five.

\section{Question Seven}

A substantial difference between the numbers of males and females completing the survey was observed in the responses to this question. Of the total number of respondents, $62 \%$ were females and only $38 \%$ were males. Based on personal observation - and the opinions of other museum professionals - this ratio mirrors female/male attendance generally to any museum. An exception to this trend appears to be military museums, which seem to attract significantly more male visitors. Also more women seemed willing to answer the survey in each of the three museums, with quite a number of men, especially single male visitors refusing to complete it. In addition many families consisting of female adults and children visited these museums, as it was the school summer holidays. Therefore a number of factors help to explain these figures.

\section{Question Eight}

In contrast to question seven, the responses to this question showed a consistent spread in terms of age ranges. In each of the three museums a significant bulk of respondents were in the 16-54 age ranges (257 respondents - 82.3\%). Of these ranges, $35-44 \mathrm{had}$ the highest percentage of respondents with $25.7 \%$. This would seem to reflect the large number of mothers visiting these museums with their children. Further research is required to establish what under $16 \mathrm{~s}$ think of human remains and the issue of life after death, compared to respondents over the age of 75 .

\section{Question Nine}

This question established the religious affinity of respondents. Christians accounted for $58 \%$ of all visitors questioned, whilst Atheists were the second largest grouping at $24.7 \%$. This gives a total of $82.7 \%$ indicating that the other major religions did not feature heavily in the visitor population $-4.7 \%$ were Jewish, $3 \%$ were Muslim and just $1 \%$ Hindu. It would have been very useful to compare the answers of respondents from the four major religions to see if they had differing views on the issue of life after death and the ethics of displaying human remains. However, due to the small number of respondents from three of these faiths, such comparisons were not viable and would not have been statistically significant. Future work with focus groups involving respondents from a variety of faiths would be a potentially useful exercise. The results obtained from the analysis of this question probably represent a general trend; that people belonging to the Hindu, Islamic, Jewish and Buddhist faiths do not visit museums in the United Kingdom in numbers which reflect their representation in the general population. It would be useful to conduct focus group research in order to establish why this is the case. 


\section{Question Ten}

This question polled the educational level of respondents. This was a two part question asking respondents when they left school and whether they had attended a form of higher or further education. Almost half of all respondents $(142=47.3 \%)$ left school at $18+$, which was taken to indicate that they went straight on to further education, while 73 respondents $(24.3 \%)$ left school at 18 . Overall, the respondents were reasonably well-educated with 231 respondents $(77.0 \%)$ going on to undertake some form of further education either at $18+$ or later in life.

Regression analysis was undertaken with the demographic data for questions seven, eight, nine and ten to see if they would predict the response given to question five. Age, religion and education did not predict the response to this question as the statistical indicator (R square), was very low. Sex may, however, affect the response to this question as there was a low significance on gender. This could be taken to indicate that men are more likely to agree to museums displaying human remains in "whatever way they see fit". Possibly men are more intuitive on this issue, or it could be that they agreed with this option as it seemed the easiest choice. Many did not consider the rest of the options when they were posed.

In general terms, most respondents supported the idea of the three museums displaying ancient Egyptian human remains in "whatever way they see fit" (82.5\%). Most also felt that they learnt something from viewing them (80\%). In terms of the specific goal to establish visitor perceptions of human remains, these are the two most important conclusions to be drawn from this survey work.

These findings are in line with previous recent museum works addressing public opinion about human remains. However, these evaluations did not directly question the public about human remains; instead visitors were encouraged to leave comments. An example of this practice is the "London Bodies" exhibition at the Museum of London which ran from October 1998 until February 1999. This was a temporary exhibition with a series of skeletons presented under perspex covers. Visitors were not directly asked what they felt about the remains, but were encouraged to leave comments voluntarily. Of the 172 comments left by the 15000 visitors to this exhibition only one negative comment was entered about the human remains (Swain 2002). More recently, visitors were asked for comments during an 18 month temporary exhibition, "Ancient Egypt: Digging for Dreams" at Croydon Clocktower and the Burrell Collection, Glasgow. This was a 120 object exhibition that featured a mummified head and hand in a display case covered by a shroud. Visitors were given the choice of whether or not to view these human remains. Comment cards were left by 254 visitors, with 146 of these mentioning the human remains. Of these 146, two-thirds of comments were positive, and the public appreciated being given the choice to view the remains. These raw data were reviewed by the author, and further research and discussion in relation to them is encouraged.

Although the anecdotal evidence from these two temporary exhibitions is not directly comparable to the results gained from the 300 respondents in the research presented 
here, the comments generally support the idea of the public being happy with viewing ancient human remains in museums.

\section{Conclusions}

Using some of the issues raised by the survey, it is useful to look to the future. Obviously, when looking at the ethics of displaying human remains, visitors are only one interested group. However, they are undoubtedly the largest and most important of all museum stakeholders. Although not as contentious as the display of Aboriginal or Native American remains, the public is generally positive about the display of ancient Egyptian remains, but we perhaps need to look to the future re-display of these remains. This has been made more timely by the fact that contentious remains in many museums have been removed from display, but those remains that are unlikely to be repatriated have been left on exhibit, thus creating a double standard. Many of the respondents viewed the remains merely as "vessels", reducing them to the level of mere objects that provide knowledge to subsequent generations. Only $14.2 \%$ of respondents stated that human remains should be displayed in a "more appropriate and respectful environment", and another 3\% felt that the present displays lack dignity.

A possible, more appropriate, future display arrangement could be a separate museum area, thereby giving visitors the choice to view the remains or not. Such a special exhibition area might be darkened with a more subdued atmosphere. This would follow the example of the "Royal Mummies" display in the Egyptian Museum in Cairo, where no photography or talking is allowed. This public control might encourage more respectful viewing. This, of course, might also elicit a certain ghoulish interest in some visitors in spite of trying to present a more appropriate and respectful display.

It is, of course, difficult to right past colonial wrongs of acquisition. There is now little chance of these remains being returned to Egypt and there have been no claims to this effect, though there have been requests to repatriate cultural objects. However, it is not just that these remains have been isolated from their original funerary contexts (as indeed most have), but none of these collections reflect on the reasons why the remains were collected in the first place. The story of their acquisition and the colonial trade in antiquities has a place in their future re-display. Visitors can then make a more informed decision about whether it is right for museums to have these human remains as well as other ancient Egyptian objects.

In addition to visitors and focus groups, curators, scientists, Egyptologists, educators and museum staff should all play a part in re-defining an appropriate final resting place for human remains in museums. Interestingly, it was the warding staff at both the British Museum and the Manchester Museum who felt most uncomfortable with the idea of the remains being in a museum. This can partly be explained by the fact that these staff see the remains on a regular basis, and as a result form a more personal connection with them. Therefore, they more than any other group of people are most aware of these public displays serving as a final resting place for the remains. Hedley Swain, co-curator of the "London Bodies" exhibition at the Museum of London, made the point that human remains should not be displayed on a permanent basis, and it is only 
appropriate in a short-term exhibition (pers. comm.). Perhaps in a permanent display of death from ancient Egypt one no longer needs to see actual human remains. If, however, these remains continue to be displayed then Carol Andrews, former curator at the British Museum, believes they should be more personalised with the names of individuals present so that visitors can recite them, just as priests in ancient Egypt would have done (pers. comm.).

Many visitors stated verbally that they "trusted" the museum to be professional in how it displayed its collections. However, this trust is perhaps not justified when we do not present the complete picture, and these human remains are treated merely as objects surrounded by other objects. Over the past decade, a number of professional museums groups, including the International Council of Museums (ICOM), have presented guidelines for museums holding human remains (ICOM 2001). Many of these were developed to deal with the issues related to the possible repatriation of human remains, but some like the Museum Ethnographers' Group guidelines deal directly with the care of human remains (Museum Ethnographers' Group 1994). However, there are no explicit guidelines relating to collections that hold remains without cultural descendants, and it is perhaps time to draw up a series of guidelines that deal directly with these collections with the parties mentioned above. It will be useful to see the outcome of the Human Remains Working Group when it reports (unpublished at time of writing), and whether they will be charged with establishing such a set of guidelines.

The results of this survey suggests that further research needs to be undertaken with visitors, focus groups and other stakeholders to try to establish more ethical displays of human remains. The statistics might point to public support for their display, however, a small minority does not support this idea, and significantly it is a 'minority' that is currently dominating repatriation claims for human remains with cultural descendants. In deciding the future of these particular human remains, it is therefore important to address all public views, not just the majority. In addition, although the results of the survey highlight the fact that re-display is not a necessity and most visitor views towards these remains are ambivalent and somewhat contradictory, $14.2 \%$ of visitors wanted a more respectful display. Museums should at least acknowledge this truth to these particular sets of human remains. 


\section{Appendix: Human Remains Survey}

1. This museum has human remains on display - what do you think human remains are?

2. After seeing these human remains do you feel that you have learnt more about the ancient Egyptians?

No

Yes

What learnt

3. Would your thoughts on this museum having human remains be different if the remains were less than one hundred years old?

No

Yes

How different

4. The ancient Egyptians believed their souls would continue to live on after death. What do you think happens to people after death?

5. Your thoughts on the museum displaying ancient Egyptian human remains can be best summed up by which one of the following:-

A The museum should be allowed to display human remains in whatever way it sees fit Discuss

B The museum should show more respect in the way it displays human remains Discuss

C It is okay for the museum to hold human remains but they should be kept in store and not displayed

Discuss

D It is not appropriate for the museum to hold human remains (go to question 6)

6. If you believe that the museum should not hold these human remains what should they do with them? The authorities in Egypt and the people who live there, have never expressed a wish for mummified remains held in museums outside Egypt to be returned. So do you think that: 
A The human remains should be buried or cremated in Britain?

B The human remains should be returned to the Egyptian authorities?

C The human remains should be re-buried in Egypt?

D The human remains should be re-buried in Egypt in their coffins with all their associated funerary ornaments and grave goods?

Discuss

Disposal in Britain would probably involve a secular form of cremation, since most of these remains are from the pre-Christian and pre-Islamic eras. The Egyptian authorities would not wish to have these remains returned. Re-burial in Egypt would pose very considerable administrative and legal difficulties, which would be very costly to resolve. Any burial with artefacts would be insecure and open to grave-robbing, unless the Egyptian authorities were to establish a protected site, which they are not minded to do.

7. Are you? Male Female

8. What age range do you belong to?

$\begin{array}{ll}\text { A } & 16-24 \\ \text { B } & 25-34 \\ \text { C } & 35-44 \\ \text { D } & 45-54 \\ \text { E } & 55-64 \\ \text { F } & 65+\end{array}$

9. Which religion do you feel most affinity with?

10. At what age did you leave school?

$\begin{array}{ll}\text { A } & \text { pre } 16 \\ \text { B } & 16 \\ \text { C } & 18 \\ \text { D } & 18+\end{array}$

10b. Have you ever attended a full-time course at university/college 


\section{References}

Bauer, H. 2001. Working Group on Human Remains. Layton, R. 1989. Conflict in the Archaeology of LivDepartment of Culture, Media and ing Traditions. London: Routledge. Sport. [http://www.culture.gov.uk/ cultural_property/wg_+human _ Museums Association 2002. Code of Ethics for Muremains.htm] [accessed: 15.09.2003]. seums (First Edition).

BodyWorlds 2002. Prof. Gunther von Hagens' Museum Ethnographers' Group 1994. Museum BodyWorlds: The Anatomical Exhibition of Real Human Bodies. [http: //www.bodyworlds.com/en/pages/ home.asp] [accessed 07.2002].

Butler, T. 2001. Government Announces Details of Working Group on Human Remains. National Health Service 2002. NHS Retained Organs Museums Journal 6, 12. Ethnographers' Group Guidelines on Management of Human Remains. [http: //www.museumethnographersgroup.o rg.uk/HumanRemainsguidelines.htm] [accessed: 07.2002]. Commission. [http://www.nhs.uk/ retainedorgans] [accessed 16.10.2003].

Chamberlain, A. 1994. Human Remains. London: British Museum Publication.

Parker Pearson, M. 1995. Ethics and the Dead in British Archaeology. The Field Archaeologist 23, 31-34.

Department of Culture, Media and Sport, Cultural Property Unit, August 2001. Working Group on Human Remains. [http:// Swain, H. 2002. The Ethics of Displaying Human www.culture.gov.uk/cultural_property/ wg_human_remains/default.htm] [15.10.2003]. Remains from British Archaeological Sites. Public Archaeology 2, 4-15.

ICOM 2001. ICOM Code of Ethics for Museums. International Council of Museums, UNESCO. [http://www.icom.museum/ ethics.html] [accessed 15.10.2003]. 